\title{
Experimental results on pancreatic juice parenteral application in broiler growing
}

\author{
Vladimir Vertiprakhov ${ }^{1,}{ }^{*}$, Alyona Grozina ${ }^{1}$, Vladimir Fisinin ${ }^{1}$, Natalya Ovchinnikova ${ }^{1}$, and \\ Muhammed Kozhokov ${ }^{2}$ \\ ${ }^{1}$ FSBSI Federal state budget scientific institution, Federal scientific center "All-Russian research and \\ technological Institute of poultry" of the Russian Academy of Sciences, 141315 Sergiyev Posad, \\ Russia \\ ${ }^{2}$ Kabardino-Balkarian State Agricultural University named after V.M.Kokov, Lenin Avenue, 1V, \\ 360030 Nalchik, Russia
}

\begin{abstract}
The paper presents the results of the use of pancreatic enzymes in the form of intramuscular injection of pure pancreatic juice obtained from fistulated chickens to broiler chickens. At 7 days of age during the formation of groups, the differences between the control and experimental chickens were $17.9 \%(p<0.05)$ in favor of the former. It was found that after the injection of the drug 1 time in 7 days, there was a stimulation of metabolism in the experimental group broilers. By 14 days of age, the differences between the groups were $17.4 \%(\mathrm{p}<0.05)$, to 21 days of age $9.1 \%$ ( $p<0.05$ ), to 28 days of age $-5.3 \%$, to 35 - day-old age $-4.9 \%$. Consequently, as the chickens were raised by 28 days of age, the chickens of the experimental group caught up with the live weight of the control ones, and, considering the increase in live weight, even exceeded this indicator $(50.1 \mathrm{~g} /$ day versus 42.7$)$. The use of parenteral pancreatic juice of chickens at a dose of $0.1 \mathrm{ml} / \mathrm{kg}$ of live weight of broiler chickens allows to conclude that the drug has a stimulating effect on poultry metabolism, manifested by an increase in live weight gain, an increase in the content of lymphocytes, as an indicator of immunity, activation of protein and mineral metabolism in the body when using an enzyme preparation.
\end{abstract}

\section{Introduction}

Pure pancreatic juice of chickens is a clear or yellowish alkaline liquid. The specific weight of juice is $1.0064-1.0108$, the content of solids is $1.8-2.2 \%$ and the $\mathrm{pH}$ level is $7.2-8.1$. The juice has proteolytic, amylolytic and lipolytic activity, and, in terms of the concentration of proteases and especially amylase, it exceeds the pancreatic juice of mammals, while being inferior to it in terms of the concentration of lipase [1]. The pancreatic proteases are trypsin, chymotrypsin, carboxypeptidases, and elastase. In the pancreas, they are in an inactive state and are activated when they enter the intestine by the enzyme enterokinase, discovered by N.P. Shepovalnikov (1899) in the laboratory of I.P. Pavlov. Among carbohydrases, $\alpha-$ amylase and invertase were found in the pancreatic juice of birds. Pancreatic lipase

${ }^{*}$ Corresponding author: vertiprakhov63@mail.ru 
disintegrates fats into monoglycerides and unsaturated fatty acids (with the release of glycerol), hydrolyzing the ester bonds of triglycerides in positions 1 and 3 .

The scientific literature contains the data on the effect of intrinsic enzymes on the function of the pancreas in rats [2] and dogs [3]. Experimental data allowed the authors to come to the conclusion on the presence of a regulatory role of pancreatic enzymes in the secretory process pursuant to the feedback principle [4-6]. Such experiments have not been performed on birds that have the specific digestive features. Therefore, we decided to fill this gap and, for the first time, to study the development in ontogenesis and morphologicaland-biochemical parameters of blood in broiler chickens against the background of parenteral use of pancreatic enzymes.

\section{Material and methods}

The experiments were performed on 20 broiler chickens of cross-selection SGC Smena from one day to 42 days of age in accordance with the requirements of the European Convention for the Protection of Vertebrate Animals used for Experiments or for other Scientific Purposes (ETS No. 123, Strasbourg, 1986) [7]. Broiler chickens were kept in the VNITIP vivarium in compliance with optimum conditions: room temperature, duration of lighting, rations (start, growth and finish) were in accordance with the recommendations of VNITIP (2014) [8]. The control group consisted of chickens with a higher live weight within the age (10 birds), the experimental group consisted of chickens with a live weight deficit (10 birds).

Pancreatic juice was obtained from laying hens with chronic pancreatic duct fistula [9] and stored in a sterile container at $-20{ }^{\circ} \mathrm{C}$. Before use, the juice was defrosted and applied being previously 10 times diluted with sterile saline solution. Chickens of the control group were injected with saline at a dose of $1.0 \mathrm{ml}$ per $1 \mathrm{~kg}$ of live weight with the frequency of 1 time in 7 days, and the chickens of the experimental group were injected intramuscularly with $0.1 \mathrm{ml} / \mathrm{kg}$ of live weight of pancreatic juice, diluted to $1.0 \mathrm{ml}$ with saline solution weekly, starting from 7 days of age.

Blood was taken from fasting chickens in the morning from the axillary vein 1 time in 7 days. For morphological studies, special vacuum tubes were used, where EDTA was used as an anticoagulant - a purple cap (sterile vacuum tubes, $4.0 \mathrm{ml}$, Jiangxi Hongda Medical Equipment Group Ltd, 39, China). For biochemical studies, tubes with lithium heparin (green cap) or with a coagulation activator (red cap) were used. Immediately after blood collection, the tube was slowly inverted 6-8 times to completely mix the blood with the reagents. A blood sample was centrifuged at $3000 \mathrm{rpm}$ for 3 minutes to separate the formed elements from plasma or serum.

Biochemical methods. The activity of trypsin in blood plasma was studied using benzoyl DL-arginine nitroanilide (BAPNA) as a substrate on a BS3000P semi-automatic biochemical analyzer (China) by the kinetic method [10]. The activity of alkaline phosphatase, the content of glucose, cholesterol, total protein, calcium, phosphorus was performed on a BS3000P semi-automatic biochemical analyzer (China) using kits from the DIAKON-VET company (RF).

Statistical methods. For statistical processing of the results, the JMP Trial 14.1.0 software was used, with the help of which the mean value (M) and the standard deviation ( \pm m) were calculated, the significance of differences was determined by the Student's t-test. Differences were considered statistically significant at $\mathrm{p}<0.05$. 


\section{Results and their discussion}

The results of the study showed that at the day-old age, broiler chickens in the experimental group had a live weight lower by $8.7 \%$ than chickens in the control group (Table 1).

Table 1. Live weight of broiler chickens of the cross-breeding SGC Smena in ontogenesis using parenteral pancreatic juice.

\begin{tabular}{|c|c|c|}
\hline \multirow{2}{*}{$\begin{array}{c}\text { Age, } \\
\text { days }\end{array}$} & Control & Group \\
\cline { 2 - 3 } & $47.1 \pm 0.74$ & $43.0 \pm 0.50^{*}$ \\
\hline 1 & $158.3 \pm 4.36$ & $130.0 \pm 0.50^{*}$ \\
\hline 7 & $419.8 \pm 11.40$ & $346.8 \pm 12.50^{*}$ \\
\hline 14 & $943.9 \pm 23.60$ & $857.8 \pm 26.20^{*}$ \\
\hline 21 & $1525.1 \pm 35.30$ & $1444.8 \pm 51.00$ \\
\hline 28 & $2239.2 \pm 82.10$ & $2130.8 \pm 78.80$ \\
\hline 35 &
\end{tabular}

Note: ${ }^{*}$ - the difference with the control group is significant at $\mathrm{p}<0.05$

It can be seen from this table that during the first 7 days of growing, the differences between the groups increased: in live weight, the experimental chickens lagged behind the control ones by $17.9 \%(p<0.05)$. On the seventh day, pancreatic juice was injected into the chickens of the experimental group in accordance with the test procedure. By 14 days of age, the differences between the groups were $17.4 \%(\mathrm{p}<0.05)$, by 21 days of age $-9.1 \%$ $(\mathrm{p}<0.05)$, by 28 days of age $-5.3 \%$, by 35 days of age $-4.9 \%$. Consequently, as the chickens were raised by 28 days of age, the chickens in the experimental group did not differ significantly from the control ones, and, considering the increase in live weight, even overtook them (Fig. 1).

To study the mechanism of the stimulating action of pancreatic enzymes used parenterally, we performed the determination of the morphological and biochemical parameters of the blood of broiler chickens (Tables 2, 3).

From this table 2 it can be seen that in the experimental group at 21 and 28 days of age, there is a decrease in the number of leukocytes in the blood (respectively, by $10.7 \%$ and $19.6 \%, p<0.05)$. At the same time, there is a change in the ratio of different forms of white blood cells in the leukocyte formula: the content of lymphocytes increases at 21 days of age (by $14.2 \%$ ) and 28 days of age (29.3\%), which indicates an increase in specific protection against bacteria and viruses. and a decrease in the overall resistance that neutrophils and eosinophils provide. A decrease in the number of erythrocytes and hemoglobin (with the exception of 35 days of age) shows a decrease in metabolism within the physiological norm. Indicators of RDW-CV and RDW-SD are connected with the erythrocyte value. The first index determines the ratio of the width of the erythrocyte to the volume (coefficient of variation). The RDW-CV index indicates the deviation of the erythrocyte volume from the mean value. Thus, pursuant to the morphological parameters of blood, broiler chickens receiving injection of pancreatic juice of chickens had lower values in the number of leukocytes and erythrocytes, which did not go beyond the physiological norm. 


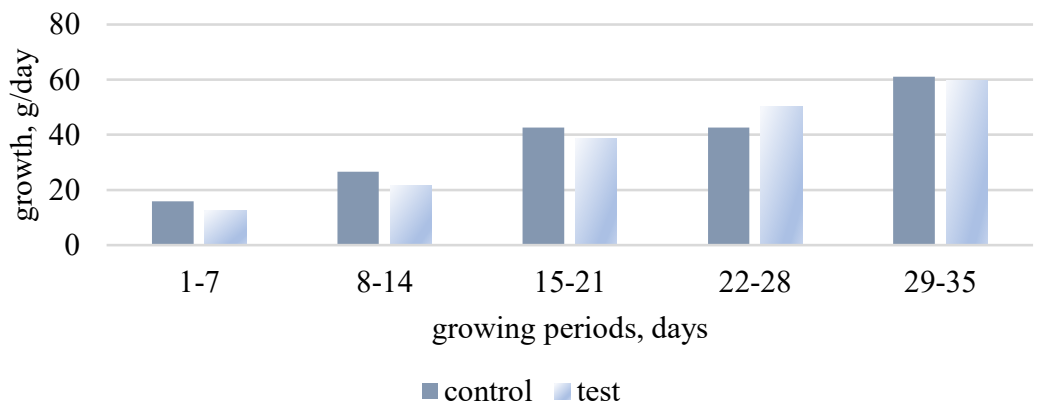

Fig. 1. Average daily gain in live weight of broiler chickens when using intramuscular injection of pancreatic juice of $0.1 \mathrm{ml} / \mathrm{kg}$ of live weight.

Table 2. Morphological parameters of the blood of broiler chickens of the SGC Smena selection using intramuscular pancreatic juice of chickens.

\begin{tabular}{|l|c|c|c|c|c|c|}
\hline \multirow{2}{*}{$\begin{array}{c}\text { Haematologic } \\
\text { al } \\
\text { indicators }\end{array}$} & \multicolumn{2}{|c|}{$\begin{array}{c}\text { Group } \\
\text { age - } 21 \text { days }\end{array}$} & \multicolumn{2}{c|}{$\begin{array}{c}\text { Group } \\
\text { age - 28 days }\end{array}$} & \multicolumn{2}{c|}{$\begin{array}{c}\text { Group } \\
\text { age - 35 days }\end{array}$} \\
\cline { 2 - 7 } & Control & Experimental & Control & Experimental & Control & Experimental \\
\hline WBC, ${ }^{109} / 1$ & $28.1 \pm 0.87$ & $25.1 \pm 0.10^{*}$ & $32.1 \pm 2.47$ & $25.8 \pm 1.25^{*}$ & $30.7 \pm 1.26$ & $28.9 \pm 2.02$ \\
\hline Neu, \% & $33.1 \pm 2.29$ & $26.9 \pm 1.86$ & $52.2 \pm 3.00$ & $43.8 \pm 1.76^{*}$ & $38.2 \pm 2.29$ & $39.9 \pm 2.6$ \\
\hline Lym, \% & $62.8 \pm 2.87$ & $71.7 \pm 2.07^{*}$ & $40.3 \pm 3.55$ & $52.1 \pm 2.46^{*}$ & $59.3 \pm 2.22$ & $57.3 \pm 2.75$ \\
\hline Mon, \% & $0.3 \pm 0.05$ & $0.3 \pm 0.07$ & $0.6 \pm 0.14$ & $0.5 \pm 0.11$ & $0.2 \pm 0.04$ & $0.2 \pm 0.01$ \\
\hline Eos, \% & $3.7 \pm 0.7$ & $1 \pm 0.24^{*}$ & $6.8 \pm 0.61$ & $3.4 \pm 0.97^{*}$ & $2.1 \pm 0.26$ & $2.4 \pm 0.42$ \\
\hline Bas, \% & $0.1 \pm 0.01$ & $0.1 \pm 0.01$ & $0.1 \pm 0.01$ & $0.1 \pm 0.01$ & $0.2 \pm 0.02$ & $0.2 \pm 0.02$ \\
\hline RBC, $10^{12} / 1$ & $2.5 \pm 0.03$ & $2.3 \pm 0.04^{*}$ & $3.0 \pm 0.09$ & $2.6 \pm 0.07^{*}$ & $2.9 \pm 0.04$ & $2.7 \pm 0.06^{*}$ \\
\hline HGB, g/1 & $134.9 \pm 1.67$ & $123.5 \pm 0.89^{*}$ & $155.1 \pm 4.33$ & $135.5 \pm 2.59^{*}$ & $153 \pm 1.56$ & $145 \pm 3.76$ \\
\hline HCT, \% & $34.3 \pm 0.31$ & $31.4 \pm 0.34^{*}$ & $38.4 \pm 1.1$ & $33.9 \pm 0.72^{*}$ & $36.9 \pm 0.36$ & $34.7 \pm 0.84$ \\
\hline MCV, fl & $135.5 \pm 0.55$ & $134.6 \pm 1.01$ & $129.7 \pm 0.57$ & $129.2 \pm 1.07$ & $126 \pm 0.68$ & $127.4 \pm 0.66$ \\
\hline MCH, pg & $53.4 \pm 0.27$ & $53 \pm 0.55$ & $52.48 \pm 0.26$ & $51.8 \pm 0.66$ & $52.3 \pm 0.29$ & $53.1 \pm 0.43$ \\
\hline MCHC, g/1 & $393.8 \pm 1.67$ & $393.8 \pm 1.57$ & $404.4 \pm 1.07$ & $401 \pm 1.79$ & $414.8 \pm 1.48$ & $417 \pm 2.15$ \\
\hline RDW-CV, \% & $11.2 \pm 0.21$ & $12.4 \pm 0.38^{*}$ & $10.4 \pm 0.07$ & $10.9 \pm 0.04^{*}$ & $10.0 \pm 0.05$ & $10.7 \pm 0.20^{*}$ \\
\hline RDW-SD, fl & $62.9 \pm 1.31$ & $69 \pm 2.32^{*}$ & $55.2 \pm 0.54$ & $57.6 \pm 0.38^{*}$ & $51.6 \pm 0.45$ & $55.4 \pm 0.77^{*}$ \\
\hline
\end{tabular}

Note: * - the difference with the control group is significant at $\mathrm{p}<0.05$

Biochemical blood tests make it possible to monitor the functional state of the body, the work of the liver, kidneys, pancreas and other organs, as well as monitor the processes of protein, carbohydrate, fat and mineral metabolism. The data are presented in Table 3.

Table 3. Biochemical parameters of broiler chickens with intramuscular administration of chicken pancreatic juice.

\begin{tabular}{|l|c|c|c|c|c|c|}
\hline \multirow{2}{*}{$\begin{array}{c}\text { Biochemical } \\
\text { indicators }\end{array}$} & \multicolumn{2}{|c|}{ Group, age 21 days } & \multicolumn{2}{c|}{ Group, age 28 days } & \multicolumn{2}{c|}{ Group, age 35 days } \\
\cline { 2 - 7 } & Control & Experimental & Control & Experimental & Control & Experimental \\
\hline Total protein, g/l & $\begin{array}{c}30.4 \pm \\
0.33\end{array}$ & $31.7 \pm 0.78$ & $1) 0.76$ & $35.2 \pm 0.51^{*}$ & $36.4 \pm 0.76$ & $38.2 \pm 0.50$ \\
\hline Trypsin, un/l & $1) 56.1$ & $1) 68.98$ & $961 \pm 49.4$ & $969.9 \pm 13.06^{*}$ & $1016 \pm 52.9$ & $1125.0 \pm 69.8$ \\
\hline Alkaline & $1) 940.20$ & $1) 878.88$ & $4567.0 \pm$ & $6492.7 \pm$ & $2429 \pm$ & $3919.0 \pm$ \\
phosphatase, un/1 & & & 313.60 & $610.00^{*}$ & 183.40 & 189.30 \\
\hline Calcium, $\mathrm{mmol} / 1$ & $2.7 \pm 0.04$ & $2.6 \pm 0.04$ & $2.6 \pm 0.09$ & $2.4 \pm 0.03$ & $2.4 \pm 0.13$ & $2.1 \pm 0.02$ \\
\hline Phosphorus, $\mathrm{mmol} / 1$ & $3.9 \pm 0.08$ & $4.2 \pm 0.29$ & $2.7 \pm 0.07$ & $2.3 \pm 0.01^{*}$ & $2.2 \pm 0.04$ & $2.4 \pm 0.11$ \\
\hline Cholesterol, $\mathrm{mmol} / 1$ & $3.1 \pm 0.09$ & $3.2 \pm 0.12$ & $3.1 \pm 0.05$ & $3.0 \pm 0.10$ & $3.4 \pm 0.03$ & $3.5 \pm 0.07$ \\
\hline Glucose, $\mathrm{mmol} / 1$ & $13.3 \pm 0.27$ & $12.1 \pm 0.53$ & $11.0 \pm 0.15$ & $11.2 \pm 0.21$ & $12.9 \pm 0.26$ & $11.6 \pm 0.81$ \\
\hline
\end{tabular}

Note: * - the difference with the control group is significant at $\mathrm{p}<0.05$

The results showed that parenteral administration of pancreatic juice affects protein and mineral metabolism. In the age range of 21-28 days, the content of total protein in the blood 
changes, increasing by $7.3 \%(\mathrm{p}<0.05)$, and the amount of total phosphorus in the experimental group also decreases by $14.8 \%(\mathrm{p}<0.05)$ and the activity of alkaline phosphatase increases by $42.2 \%(\mathrm{p}<0.05)$.

Enzyme preparations are widely used in cattle breeding and poultry farming, usually as feed additives [11]. In medicine, there is a drug for parenteral administration - crystalline trypsin, but such drugs are not widely used due to the poor knowledge of the mechanism of action of pancreatic enzymes when administered intramuscularly to the body as a whole [12]. We studied the level of trypsin and nitric oxide metabolites in the postprandial phase. The regularity of the parallel increase in the content of physiological NO donors and the activity of trypsin in the blood after feeding the bird was established [13], which is associated with parasympathetic regulation, since the atropine administered preliminarily blocked an increase in the secretory function of the pancreas. In this work, for the first time, an experiment was performed on poultry, which allows to study the mechanism of action of native pancreatic juice on the organism of broiler chickens. As a result, it was found that the most significant changes in the metabolism of broiler chickens occur in the experimental group due to the stimulation of protein and mineral metabolism. This is consistent with an increase in live weight and morphological changes in the composition of the bird's blood. Questions of further use of the preparation in the form of an aerosol for mass processing of poultry are discussed.

\section{Conclusions}

The use of parenteral pancreatic juice of chickens at a dose of $0.1 \mathrm{ml} / \mathrm{kg}$ of live weight of broiler chickens allows to conclude that the drug has a stimulating effect on poultry metabolism, which manifests itself in an increase in live weight gain, an increase in the content of lymphocytes, as an indicator of immunity, activation of protein and mineral metabolism. in the body when using an enzyme preparation.

\section{References}

1. V. I. Fisinin, V. G. Vertiprakhov, Ye. L. Kharitonov, A. A. Grozina, Agricultural Biology, 54(6), 1122 (2019)

2. J. S. Laporte, J. Tremolieres, Comptes rendus de l'Académie des Sciences, 273, 1205 (1971)

3. P. K. Klimov, A. A. Fokina, Physiology of the Pancreas. Regulation of exocrine function (1987)

4. A. S. Loginov, N. Sh. Amirov, O. D. Chernoyarova, Physiological Journal of the USSR, 67, 957 (1981)

5. G. F. Korotko, Journal of Fundamental Medicine and Biology, 2, 4 (2016)

6. S. Rothman, C. Leibow and L. Isenman, Physiological Reviews, 82, 1 (2002)

7. European Convention for the Protection of Vertebrate Animals used for Experimental or Other Scientific Purposes (ETS №. 123) (Strasbourg, 1986) http://www.conventions.ru

8. Guide to Optimizing Poultry Compound Feed Recipes (2014)

9. Ts. Zh. Batoev, Physiology of Bird Digestion (2001)

10. V. G. Vertiprakhov, A. A. Grozina, Veterinary, 6, 51 (2018)

11. I. A. Yegorov, V. A. Manukyan, V. G. Vertiprakhov, T. N. Lenkova, T. A. Yegorova, I. N. Nikonov, A. A. Grozin, K. V. Borisenko, Poultry farming, 9-10, 61 (2019) 
12. V. G. Vertiprakhov, A. A. Grozina, Method for normalizing digestion in animals by parenteral administration of pancreatic enzymes. Patent for invention 2738930, 12.18.2020. Claim №. 2019139198 dated 03.12.2019

13. V. Y. Titov, A. V. Ivanova, A. N. Osipov, A. M. Dolgorukova, V. G. Vertiprakhov, N. A. Slesarenko, I. I. Kochish, Bulletin of Experimental Biology and Medicine, 168(3), 321 (2020) 